\section{International Scientific Journal Theoretical \& Applied Science}

p-ISSN: 2308-4944 (print) e-ISSN: 2409-0085 (online)

Year: $2014 \quad$ Issue: 12 Volume: 20

Published: $30.12 .2014 \quad \underline{\text { http://www.T-Science.org }}$
Evgeniy Reutskiy

post graduate student

National aviation university, Ukraine

evgeniyr@ukr.net

Leonid Scherbak

doctor of technical science, professor

National aviation university, Ukraine

SECTION 4. Computer science, computer engineering and automation.

\title{
THE METHOD OF FORECASTING CHARACTERISTICS OF METROLOGICAL RELIABILITY INFORMATIONAL-MEASURING SYSTEMS
}

Abstract: In this paper the method of forecasting characteristics of metrological reliability informationalmeasuring system is offered and grounded: reliability function and metrological resource. The results of forecasting and estimation of its accuracy example are given.

Key words: reliability function, metrological resource, failure, forecasting, stochastic process, informationmeasuring system.

Language: English

Citation: Reutskiy E, Scherbak L (2014) THE METHOD OF FORECASTING CHARACTERISTICS OF METROLOGICAL RELIABILITY INFORMATIONAL-MEASURING SYSTEMS. ISJ Theoretical \& Applied Science 12 (20): 31-36. doi: http://dx.doi.org/10.15863/TAS.2014.12.20.8

\section{Introduction}

State-of-the-art-industry measuring equipment is highly-accurate and automated. It has found common use in different branches of the industry and technological processes. Suitable effect of measuring appliance systems is obtained by proper exploitation and qualitative technical maintenance. In turn, proper exploitation of measuring system is planned according to analysis results of it's technical maintenance and verification.

One of the special aspects of measuring systems exploitation is appearance of hidden metrological failures, what cause necessity for proper planning of technical maintenance and verification, which will give a chance to control appropriate level of metrological reliability of measuring systems. As metrological reliability criteria nonfailurity (nonfailure operating probability) and life (metrological resource) characteristics are used the most often. In this regard the task for developing of forecasting method of the metrological reliability characteristics for measuring systems, which takes into account special aspects of it's exploitation is relevant objective.

Analysis of publications
Problems and tasks of providing metrological reliability information-measuring system (IMS) constantly draw attention of homeland scientists and researches. Estimation of the level of metrological reliability for measuring devices were examined in labors [1-6]. Which take place in the process of production manufacturing; determination of metrological failure probability, probabilisticphysical failure models; monitoring of metrological probability IMS methods. In publications [1, 4] authors on the base of Markov's chains developed mathematical model of metrological reliability of precision measuring device forecasting and based procedure of the construction of nomographic charts for determination of technical resource of measuring channels. In spite of increasing quantity of scientific works, the task of determination of metrological resource and reliability function of IMS remains challenging. Solving of this task will render possible to control the characteristics of metrological reliability of the system on the stage of it's exploitation with account for data of measuring during verification or calibration.

In this investigation the method of forecasting characteristics of metrological reliability IMS on the base of statistic data processing of measurement 
using mathematical instrument of the theory of runs of the stochastic processes is offered.

\section{Determination of reliability function}

In general terms error of IMS is described with nonstationary stochastic process $\xi(\omega, t), \omega \in \Omega, t \in T$. For fixed timing as metrological characteristic model the cross section of the stochastic process is used $\xi_{j}(\omega)=\left.\xi(\omega, t)\right|_{t=t_{j}}$, what gives a chance to use statistic estimates of error for suitable researches.

Let error of measuring be described with Gauss stochastic process with joint density probability $p(x, y, t)$ and with it's derivative, then

$$
p(x, y, t)=\lim _{\Delta t \rightarrow 0}\left\lfloor p_{\xi}(x, x+y \Delta t) \Delta t\right\rfloor .
$$

Joint density probability of Gauss stochastic process is equals to

$$
\begin{aligned}
& p_{\xi}(x, y)=\frac{1}{2 \pi \sigma_{1} \sigma_{2} \sqrt{1-r^{2}}} \exp \left[-\frac{1}{2\left(1-r^{2}\right)^{\times}} \times\right. \\
& \left.\times\left(\frac{\left(x-a_{1}\right)^{2}}{\sigma_{1}^{2}}-2 r \frac{\left(x-a_{1}\right)\left(y-a_{2}\right)}{\sigma_{1} \sigma_{2}}+\frac{\left(y-a_{2}\right)^{2}}{\sigma_{2}^{2}}\right)\right],
\end{aligned}
$$

where $a_{1}$ and $a_{2}$ are estimates of medium value, $\sigma_{1}$ and $\sigma_{2}$ are estimates of standard deviation, $r\left(t_{1}, t_{2}\right)$ is estimate of correlation coefficient of stochastic process $\xi(\omega, t)$ at the moments $t_{1}$ and $t_{2}$.

Taking into account resumption about stationary of stochastic process $\xi(\omega, t)$ and presented expression for joint density probability formula (1) will be rewritten as follows

$$
v=\frac{1}{2 \pi \sigma_{x} \sigma_{y}} \exp \left[-\frac{\left(\xi_{g}-a\right)^{2}}{2 \sigma_{x}^{2}}\right] \int_{t_{1}}^{t_{2}} y \exp \left(-\frac{(y)^{2}}{2 \sigma_{y}^{2}}\right) d y .
$$

Having calculated integral in expression and having multiplied it by normalizing multiplication factor $\frac{a_{x}}{a_{y}}$, which takes into account systematical component of the error, formula for finding medium frequency will be obtained the medium frequency of runs of the process $\xi(\omega, t)$ on the interval $\left[t_{1} ; t_{2}\right]$ can be set with next expression

$$
v(t)=\int_{t_{1}}^{t_{2}} y p(x, y, t) d y .
$$

In order to calculate expression (1) joint density probability $p(x, y, t)$ needed to be found. It will be found using probability density function $p_{\xi}(x, y)$ of stochastic process $\xi(\omega, t)$, where $x=\xi\left(t_{1}\right), y=\xi\left(t_{2}\right)$ error value in the moments of checking $t_{1}$ and $t_{2}[8]$,

$$
v=\frac{\sigma_{y}}{2 \pi \sigma_{x}} \exp \left[-\frac{\left(\xi_{\partial o n}-a\right)^{2}}{2 \sigma_{x}^{2}}\right] \frac{a_{x}}{a_{y}},
$$

where $\xi_{g}$ is admissible limit value of error IMS.

Taking into account, that stochastic process runs $\xi(\omega, t)$ create Poisson flow of happenings, reliability function $P(t)$ and probability of the onset of metrological failure of IMS $Q(t)$ are accordingly equals to [8]

$$
P(t)=e^{-v \cdot t}, Q(t)=1-P(t) .
$$

In standard technical documentation for IMS are projected time of operation until first failure, reliability function or admissible values of the probability of metrological failure are indentified. During tests estimation of real values of reliability function in periods of exploitation or maintenance of IMS are carried out. Obtained informational resources give a chance to carry out estimation and forecasting of values reliability function of IMS.

Lets us consider an example. We research one measuring channel IMS of energy carrier, summary error is equals to $\delta_{a d m}=0,5 \%$, operating till failure $T_{f}=25000 h$, reliability function $P_{0}(t)=0,95$, at fixed timing the value of reliability function $P_{j}(t)$ and the onset of metrological failure will be found $Q_{j}(t)$, by and between interval $t_{j}=8300 h$ and put obtained results in the table 1 down.

\section{Dependency relation of the onset of failure on frequency runs and time of operating until failure}

Table 1

\begin{tabular}{|c|c|c|}
\hline Frequency of runs $v_{j}(t)$ & $\begin{array}{c}\text { Onset of metrological failure } \\
\text { probability } Q_{j}(t)\end{array}$ & Time of operating until failure, $T_{j}, h$ \\
\hline 0,051 & 0,05 & 8300 \\
\hline 0,102 & 0,097 & 16600 \\
\hline 0,163 & 0,15 & 24900 \\
\hline
\end{tabular}

ISPC European Research, 
In order to calculate theoretically-predicted values of reliability function $P_{j}(t)$ statistical estimation of metrological characteristic model $A_{j+1}(t)[7]:$

$$
A_{j+1}(t)=\tilde{\sigma}(0)+0,9 \Delta_{j+1} \tilde{\sigma}\left(t_{j+1}\right)+0,1 \Delta_{j+1} \tilde{\sigma}\left(t_{j+1}\right)^{2}
$$

where $\tilde{\sigma}(0)$ is standard deviation estimate at $t=0 ; \Delta_{j+1} \tilde{\sigma}\left(t_{j+1}\right)=\tilde{\sigma}\left(t_{j}\right)-\tilde{\sigma}(0)$ is incrementation of standard deviation estimate at $t_{j+1} ; 0,9$ and 0,1 are weight coefficient, their values are grounded on the base of statistical data processing.

Having substituted suitable results of measurement in expressions (4), (2) and (3) was resumed table 2 with theoretically-predicted data of the onset of metrological failure probability.

For measuring devices, which are used for data transmission about size of measuring unit, tolerance range of the values of metrological failure probability is equals to $[0,005 ; 0,15]$. Lets us analyze obtained data in table values of the onset failure probability. On the third year of the exploitation IMS value $\mathbf{Q}_{3}(t)=0,184$ (table 2) is received, wherefore were carried out regulating operations, modernization of measuring channel and were restored operation of IMS with errors, which do not exceed admissible limits.

Table 2

Theoretically-predicted values dependency relations of the onset failure probability on frequency runs and time operating until failure

\begin{tabular}{|c|c|c|}
\hline Frequency of runs $v_{j}(t)$ & $\begin{array}{c}\text { Onset of metrological failure } \\
\text { probability } Q_{j}(t)\end{array}$ & Time of operating until failure, $T_{j}, h$ \\
\hline 0,112 & 0,106 & 33200 \\
\hline 0,173 & 0,159 & 41500 \\
\hline 0,204 & 0,184 & 49800 \\
\hline
\end{tabular}

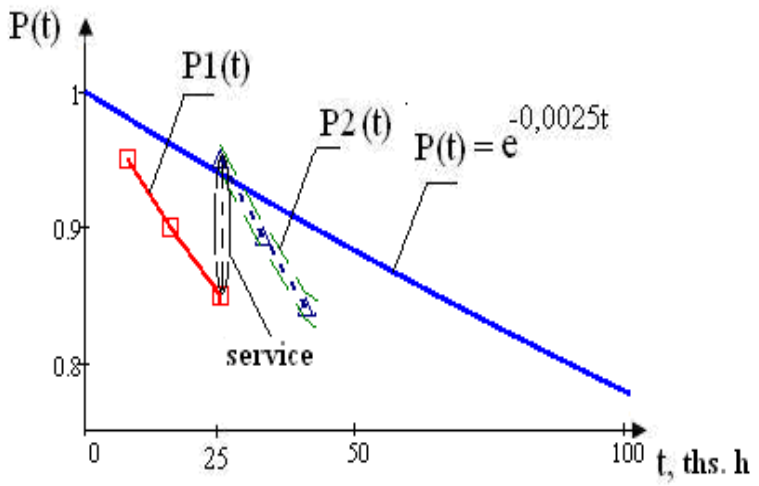

Figure 1 - Plot of operating until failure:

$P(t)$ - projected reliability function;

$P_{1}(t)$ - calculated values of reliability function;

$P_{2}(t)$ - theoretically-predicted values of reliability function

Thereafter, as table 2 shows, increasing running time or time ofmaintenance IMS, will increase the onset of metrological failure probability, what causes necessity for caring out the control more often then it's mentioned in standard technical documentation, for the purpose of avoiding the appliance of measuring result, which are distorted by the means of metrological failures.
Putting to use the data in table 1 and 2, lets us to graph the dependence of no-failure operation IMS on time operation until failure (fig.1).

Forecasting of metrological resource IMS

As is known, metrological resource is determined by time operating until metrological failure, that is exit time of error IMS out of admissible limits. From the theory of reliability to 
characterize life of IMS are outlined notions medium and gamma-percentile resources.

Gamma-percentile resource - is operating time, during which IMS will not come to it's edge state with pre-set probability $\gamma, \%$ [9]. It's calculated by following equation

$$
P\left(T_{p \gamma}\right)=1-\int_{0}^{T_{p \gamma}} f_{p}(t) d t=\frac{\gamma}{100},
$$

where $P\left(T_{p \gamma}\right)$ is probability of proving resource $T_{p \gamma}$, which is equals to value $\gamma / 100 ; f_{p}(t)$ is density function of resource for IMS of one type.

The most common distribution of metrological failures is a Gaussian distribution law of resource, it was explained as a result of research (5)

$$
f_{p}(t)=\frac{1}{s \sqrt{2 \pi}} \exp \left[-\frac{\left(t-T_{p \gamma}\right)^{2}}{2 s^{2}}\right] .
$$

Thus to forecast metrological resource of the group of IMS one should carry out the control of the resource density function IMS, forecasting of standard deviation and monitoring of probability of proving resource $P\left(T_{p \gamma}\right)$ in exploitation in determined interval time.

Figure 2 shows an example of forecasting metrological resource (Fig. 2). Functions $f_{p}\left(t_{1}\right)$ and $f_{p}\left(t_{2}\right)$ are built on the basis of statistical analysis of the measurement data that are obtained from control checks; $f_{p}\left(t_{3}\right)$ is the forecasting estimation of density function.

Figure 3 shows the forecasting probability of proving resource during operation, this figure was obtained from first research and in the future will need to check its compliance with the real values of probability.

\section{Estimating of forecasting accuracy}

Forecasting accuracy has quite a challenge because it's absolutely impossible to get an accurate forecast. As far as forecasting value is close to the true can be estimated only approximately. We consider a method of estimating the forecasting error for the empirical data which are derived from the results of tests in use.

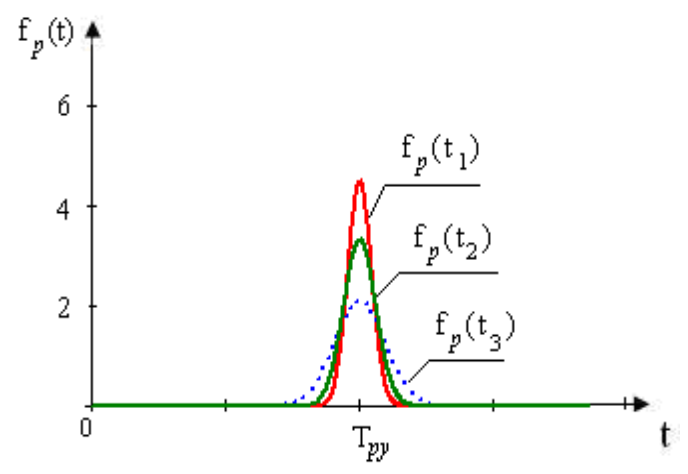

Figure 2 - Dynamics of the density distribution of the resource IMS during operation

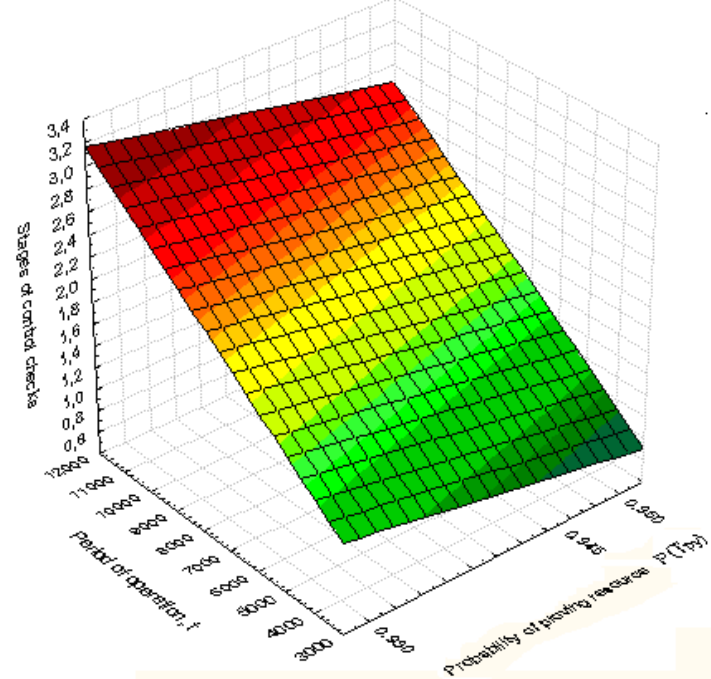

Figure 3 - Dependence of the probability of proving resource of the period of operation IMS 
In order to estimate the error in the forecasting of changes in the technical serviceability of the IMS on a priori information, subject to the following conditions [10]:

- the availability of information about changing the functions of efficiency IMS;

- IMS must undergo lengthy performance

- $\quad$ tests to determine their durability;

- it will be held forecasting changes characteristic curves of IMS that was obtained in forecasting $t_{j}$ so until their out of range.

When we'll forecast changes in the characteristics of the $\sigma(t)$ in a given time domain $t_{j}, j=\overline{1, n}$ a few steps forward and compare with the true meaning of the $\sigma_{i}\left(t_{n+j}\right)$ with the forecasting $\sigma_{f}\left(t_{n+j}\right)$ we'll get the relative importance of the forecasting error $\delta_{j}(7)$

$$
\delta_{j}=\left|\frac{\sigma_{i}\left(t_{n+j}\right)-\sigma_{f}\left(t_{n+j}\right)}{\sigma_{s}}\right| \cdot 100 \%,
$$

where $\sigma_{s}$ - the initial value of the characteristic $\sigma(t)$.

Table 3 shows the results of estimating the forecasting error in the determination of the probability of a period of three years of operation IMS.

\section{Estimation of the forecasting error performance reliability function}

Table 3

\begin{tabular}{|c|c|c|c|}
\hline Initial value $\sigma_{s}$ & $\begin{array}{c}\text { Forecasting value } \\
\sigma_{f}\left(t_{n+j}\right)\end{array}$ & Real value $\sigma_{i}\left(t_{n+j}\right)$ & Forecasting error $\delta_{j}, \%$ \\
\hline 0,01000 & 0,01050 & 0,01030 & 2 \\
\hline 0,01000 & 0,01100 & 0,01114 & 1,4 \\
\hline 0,01000 & 0,01180 & 0,01162 & 1,8 \\
\hline
\end{tabular}

\section{Conclusions}

In this article was based methods of forecasting the characteristics of metrological reliability IMS. Calculation of the reliability function based on the theory of runs of the stochastic processes, also improved expression for finding the amount of runs by taking into account random and systematic components of the metrological characteristics, there are shown results of modeling. As a forecasting of durability IMS proposed to use its metrological resource. Its forecasting is based on the determination of changes in the function of the standard deviation and the monitoring of the probability of proving resource.

These results show the estimation accuracy of forecasting higher the value of the forecasting error. Therefore future research will need to take into account the factors that affect the accuracy of forecasting and improve it.

\section{References:}

1. Vitkin LM, Ignatkin VU (2008) Ocinka j prognozuvannja metrologichnoi' nadijnosti zasobiv vymirjuval'noi' tehniky. Kharkov: [b.v.], 100.

2. Vitkin LM, Ignatkin VU, Ignatkina JV, Surdu MM (2012) Rozroblennja modeli prognozuvannja mozhlyvoi' kil'kosti vidmov ZVT. Metrologija ta prylady. No. 6. pp. $52-$ 55 .

3. Kondratov VT (2010) Metronyka, verojatnostno-fyzycheskye modely metrologycheskyh otkazov sredstv yzmerenyj $\mathrm{y}$ yh grafycheskye portretu. Vymirjuval'na ta obchysljuval'na tehnika $\mathrm{V}$ tehnologichnyh procesah. No. 1. pp. $25-35$.

4. Malovyk KN, Judyn AV (2010) Razrabotka nomogramm dlja ocenyvanyja metrologycheskoj nadezhnosty yzmerytel'nuh kanalov. Ukrai'ns'kyj metrologichnyj zhurnal. No 2. pp. $45-47$.

5. Mykyjchuk MM (2009) Aktual'ni pytannja metrologichnoi' nadijnosti promyslovyh ZVT. Metody ta prylady kontrolju jakosti. No. 23. pp. $57-60$.

6. Reuc'kyj JA, Shherbak LM (2013) Zadachi monitoryngu metrologichnoi' nadijnosti 
zasobiv vymirjuval'noi' tehniky. Materialy $\mathrm{HI}$ Mizhnarodnoi' naukovo-tehnichnoi' konferencii' «AVIA-2013»: m. Kyi'v, 21-23 travnja, 2013: tezy dop. T. 1. pp. $1.49-1.52$.

7. Reuc'kyj JA, Shherbak LM (2011) Metod prognozuvannja metrologichnyh harakterystyk dlja vyrishennja zavdan' nadijnosti zasobiv vymirjuvan'. Elektronika ta systemy upravlinnja. No 3(29). pp. $128-131$.

8. Ushakov YA, Beljaev JK, Bogaturev VA, Bolotyn VV, etc. (1985) Nadezhnost' tehnycheskyh system: Spravochnyk. Moscow: Radyo y svjaz', 608.

9. Vasilevs'kyj OM, Podzharenko VO (2010) Normuvannja pokaznykiv nadijnosti tehnichnyh zasobiv: navchal'nyj posibnyk. Vinnycja: VNTU, 129.

10. Lukashyn JP (2003) Adaptyvnue metodu kratkosrochnogo prognozyrovanyja vremennuh rjadov: Ucheb. Posobye. Moscow: Fynansu y statystyka, 416. 